\title{
Experimental Study and Kinetic Modeling of Decoking of Pacol Process Dehydrogenation Catalyst
}

\author{
M. Toghyani ${ }^{1}$, A. Rahimi ${ }^{*}$, M. Mamanpoush ${ }^{3}$, R. Kazemian ${ }^{3}$, A.H. Harandizadeh ${ }^{1}$ \\ ${ }^{1}$ Chemical Engineering, Department of Chemical Engineering, College of Engineering, \\ University of Isfahan, Isfahan, Iran \\ ${ }^{2}$ Department of Chemical Engineering, College of Engineering, University of Isfahan, \\ Isfahan, Iran \\ ${ }^{3}$ College of Chemical Engineering, Isfahan University of Technology, Isfahan, Iran
}

Received: 18th September 2014; Revised: 28th February 2015; Accepted: 9th March 2015

\section{Abstract}

The $\mathrm{Pt} / \gamma-\mathrm{Al}_{2} \mathrm{O}_{3}$ catalyst life time was limited by the formation of coke on the external and internal surfaces of catalyst in dehydrogenation reactors. The kinetics of decoking of dehydrogenation catalyst was studied in a pilot scale fixed bed reactor experimentally. The effects of temperature, oxygen concentration and other operating conditions on decoking process were investigated. A kinetic model was developed to describe the decoking of mentioned catalyst. An objective function was defined as the sum of squares of the deviations among the calculated and plant data. Accordingly the appropriate values were found in order to minimize this function. It was concluded that there was a good agreement between simulation results and experimental data. (C) 2015 BCREC UNDIP. All rights reserved.

Keywords: Decoking; $\mathrm{Pt} / \gamma-\mathrm{Al}_{2} \mathrm{O}_{3}$ Catalyst; Kinetic Modeling; Dehydrogenation process; dehydrogenation reactors; Pacol Process

How to Cite: Toghyani, M., Rahimi, A., Mamanpoush, M., Kazemian, R., Harandizadeh, A.H. (2015). Experimental Study and Kinetic Modeling of Decoking of Pacol Process Dehydrogenation Catalyst. Bulletin of Chemical Reaction Engineering \& Catalysis, 10 (2): 155-161.

(doi:10.9767/bcrec.10.2.7357.155-161)

Permalink/DOI: http://dx.doi.org/10.9767/bcrec.10.2.7357.155-161

\section{Introduction}

Industrial processes which include hydrocarbon reactants are likely to lead side reactions producing carbonaceous residues in catalyst pores and surface referred to as coke. The amount of coke formed in catalyst is estimated to be $10 \%$ or even $20 \%(\mathrm{w} / \mathrm{w})$ [1]. The formation and deposition of coke will lock the pores of

* Corresponding Author.

E-mail: rahimi@eng.ui.ac.ir (A. Rahimi),

Tel.: +983137934033, Fax: +983137934031 catalysts and cover the active metal sites resulting in catalyst deactivation [2, 3]. It is proven that there is a direct relation between the amount of coke and the aromatic content of the feed $[4,5]$.

Spent catalyst is regenerated to remove coke which collects on the catalyst during the process. For this purpose, the coke is reacted with diluted oxygen stream in a fixed, moving or fluidized bed reactor. In this process the catalyst is exposed to a very hot stream of a gas mixture containing a certain percentage of oxygen. Regeneration of coked catalysts influenced by several parameters such as the nature of coke 
(light or graphitic) and catalyst's metallic phase; therefore decoking process of a given catalyst must be treated as a particular case [6]. Accordingly the age of the catalyst, composition and purity of feedstock, products formed and the operating conditions such as temperature and pressure should be considered.

Coke burning is one of the important noncatalytic gas-solid reactions. So far, many studies have been and are conducted on the kinetics of this reaction. Both the carbon and hydrogen are present in the coke structure; consequently, in some kinetic studies two separate parallel reactions are considered where the kinetics parameters are calculated separately [7-10]. The amount of hydrogen in the coke is very low, so in most cases the hydrogen reactions can be neglected [11-15].

Dehydrogenation reaction of $\mathrm{C}_{11}-\mathrm{C}_{14}$ normal paraffins into mono-olefins (UOP $\mathrm{Pacol}^{\mathrm{TM}}$ process) is the main stage in Linear Alkyl Benzene (LAB) production process in which the alumina supported platinum catalyst is used. The high temperatures and low pressures necessary to achieve high equilibrium conversions are conducive to a rapid formation of coke. Field and process studies through previous years indicate that the rate of coke formation and catalyst deactivation in this process is noticeable and the catalyst loses its initial activity through 60-75 days. Accordingly, for an economic production capacity of LAB a large amount of deactivated catalyst is produced annually. Undoubtedly, this is a drawback economically and environmentally.
It is crucial to know the behavior of coke burning process in order to obtain the optimum operating conditions to minimize the cost of regeneration and to avoid the destruction of the catalyst $[13,14]$.

The kinetics of decoking of catalysts used in well-known processes including cracking of heavy oil, hydro desulphurization and reforming of naphtha into high octane gasoline is well known [9, 11, 12]. In general, few studies are reported in the relevant literature regarding the kinetics of decoking of paraffin dehydrogenation catalyst.

In this study the kinetics of decoking of dehydrogenation catalyst is studied experimentally in a pilot scale fixed bed reactor. Through these experiments the effect of temperature, oxygen concentration and other operating conditions on decoking process are investigated. Based on the obtained experimental data activation energy and reaction order with respect to oxygen and residual coke are evaluated for the coke burning of $\mathrm{Pt} / \gamma-\mathrm{Al}_{2} \mathrm{O}_{3}$ catalyst used in commercial paraffin dehydrogenation unit. Different kinetics model are examined and based on the accuracy of the model results, the best model is fitted and presented.

\section{Materials and Methods}

\subsection{Catalyst characterization}

The catalyst is characterized structurally. The combustion method is adopted in order to determine the initial and final amount of coke on a commercial coked catalyst (Table 3). Sur-

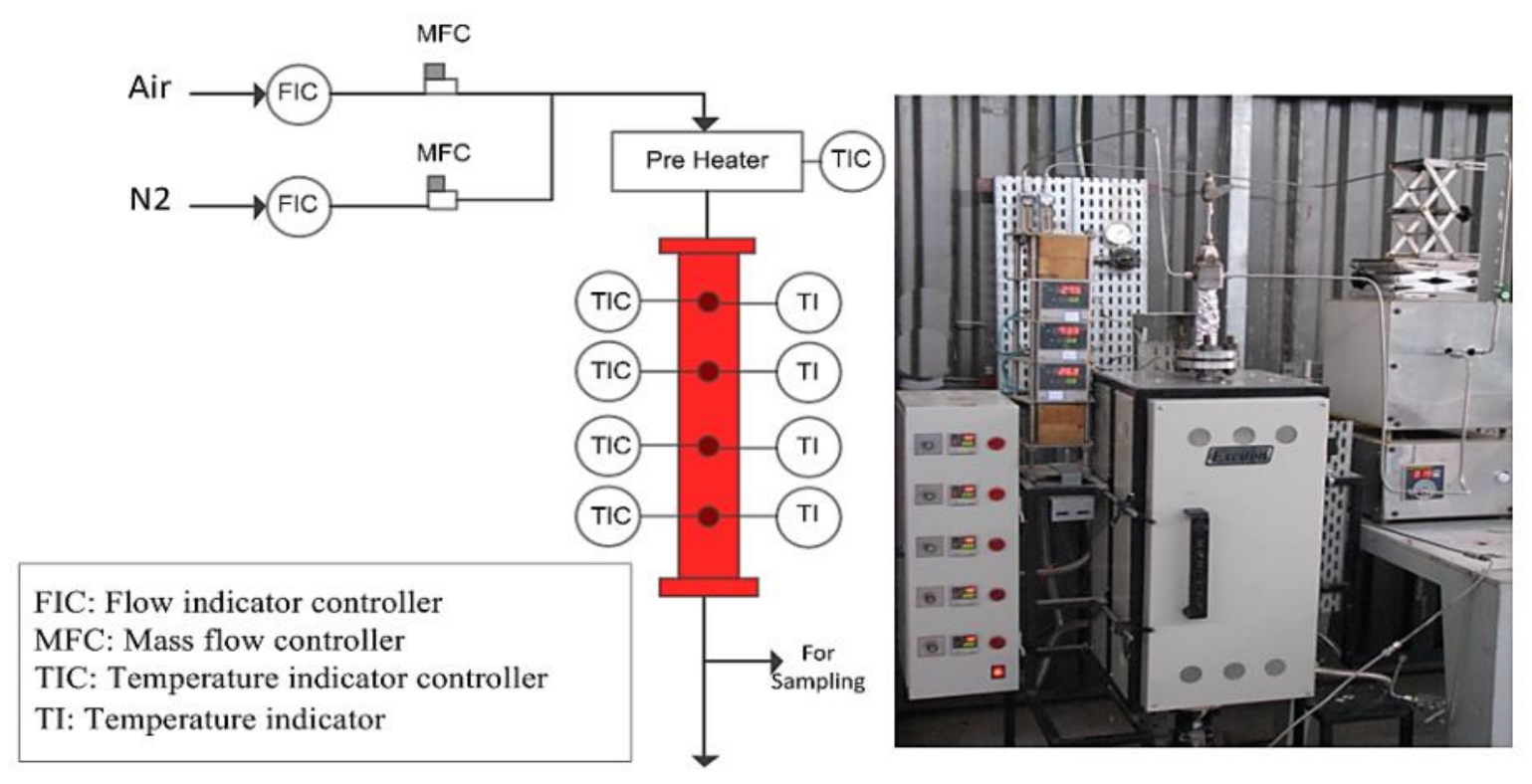

Figure 1. Diagram of experimental set-up 
face morphology is examined using Scanning Electron Microscopy (SEM) method. The catalyst characterizations are summarized in Table 1.

\subsection{Lab-scale reactor and experiments conditions}

In order to obtain the required data of coke burning, a pilot scale fixed bed reactor is used. All of the fluid flow paths are designed similar to the major commercial decoking reactor. In order to heat the reactor inlet stream to reach the required reaction temperature, a spiral tube pre-heater is used (Figure 1).

In regeneration process first, initial heating and volatile material purging take place through nitrogen; which increases the catalyst bed temperature to the required reaction level. Then certain percentage of air together with nitrogen enters the reactor and decoking process begins. The reaction zone was heated by a set of electrical heaters equipped with a temperature controller to control the temperature of the reactor wall. The temperature measurements were carried out with a digital thermocouple with a measuring precision of about $\pm 0.5{ }^{\circ} \mathrm{C}$ (model TPT979H, Terminator Company, USA). In order to achieve the specified percent of oxygen in inlet gas mixture, two mass flow controllers (MFC) were used to adjust the flow rate of nitrogen and air streams.

Major parameters affecting the rate of decoking includes: initial coke load, temperature, and $\mathrm{O}_{2}$ percent in decoking gas. In order to evaluate the effect of each parameter a set of experiments are designed by considering the range of operating parameters in Table 2. The

Table 1. Characteristic data of the dehydrogenation catalyst

\begin{tabular}{lc}
\hline \multicolumn{1}{c}{ Designation (company) } & $\begin{array}{c}\text { NDC-8 } \\
\text { (Sinopec, China) }\end{array}$ \\
\hline $\begin{array}{l}\text { Composition in wt.\%: } \\
\text { Pt/Cl (rest } \mathrm{Al}_{2} 0_{3} \text { ) }\end{array}$ & $0.43 / 0.03$ \\
$\begin{array}{l}\text { Specific internal BET- } \\
\text { surface area aBET (fresh } \\
\text { catalyst) }\end{array}$ & $140 \mathrm{~m}^{2} / \mathrm{g}$ \\
$\begin{array}{l}\text { Geometry: diameter of } \\
\text { granules }\end{array}$ & $1.25-2.2 \mathrm{~mm}$ \\
$\begin{array}{l}\text { Catalyst bulk density } \rho \mathrm{B} \\
\text { Total Pore Volume }\end{array}$ & $0.31-0.35 \mathrm{~T} / \mathrm{m}^{3}$ \\
$\begin{array}{l}\text { Comprehensives } \\
\text { strength }\end{array}$ & $1.0 \mathrm{ml} / \mathrm{g}$ \\
\hline
\end{tabular}

results of each experiment in terms of reaction time and residual coke are presented in Table 3.

\section{Results and Discussion}

\subsection{Catalyst morphology and coke content}

Based on the analysis carried out for determining the initial amount of coke, the initial coke content of the spent catalyst is estimated at about $7 \%(\mathrm{w} / \mathrm{w})$. The surface morphology of catalyst is identified through SEM test. The SEM images of the catalyst in both the regenerated as well as the deactivated conditions for center and surface of the catalyst are illustrated in Figure 2. As shown in this figure, the coke burning at the catalyst surface is more uniform and complete than the center.

Ahmed et al. have introduced two main types of coke deposition formation on $\mathrm{Pt} / \mathrm{Al}_{2} \mathrm{O}_{3}$ catalyst: hard and soft coke [6]. The observations in this study include these two types. The obtained coke loads of one of the experiments in due course are applied to introduce the X-time diagram presented in Figure 3. As shown here two zones appear crossed by a fitted curve.

In zone 1 the rate of decoking is high at initial times and then it decreases, this is due to the fact that the soft coke content of the catalyst is burnt first. Slowdown of the burning rate at the end of the first zone is because of the soft coke content reduction.

By entering the second zone, the rate is increased gradually. The fact is that the hard coke burns slower. Since the accumulation of heat on the catalyst through soft coke burning, the reactor temperature states high; hence, a gradual increase in the rate at zone 2 is observed. Such a trend of coke load during the time is observed only in mild decoking processes (e.g. Figure 2). By using higher compositions of oxygen, this trend is not observed. In fact for the quick decoking the clear boundary

Table 2. Range of operating conditions for different set of experiments

\begin{tabular}{lc}
\hline \multicolumn{1}{c}{ Parameter } & Range \\
\hline Temperature $\left({ }^{\circ} \mathrm{C}\right)$ & $400-500$ \\
Pressure (bar) & $1-3$ \\
GHSV (hr-1) & $1000-2000$ \\
Oxygen composition (-) & $0.03-0.21$ \\
$\begin{array}{l}\text { Time of decoking process } \\
\text { (min) }\end{array}$ & $0-90$ \\
\hline
\end{tabular}




\begin{tabular}{|c|c|c|c|}
\hline \multirow{2}{*}{\multicolumn{4}{|c|}{$\begin{array}{c}\text { Bulletin of Chemical Reaction Engineering \& Catalysis, } 10 \text { (2), 2015, } 158 \\
\text { Table 3. Obtained experimental data }\end{array}$}} \\
\hline & & & \\
\hline Temperature $\left({ }^{\circ} \mathrm{C}\right)$ & yо2 $(-)$ & Time (min) & $\mathrm{X}$ (kg $\left.\mathrm{kgke}_{\text {cok }} / \mathrm{kg}_{\text {cat. }}\right)$ \\
\hline \multirow[t]{24}{*}{500} & 0.03 & 0 & 0.0686 \\
\hline & & 15 & 0.0540 \\
\hline & & 30 & 0.0528 \\
\hline & & 45 & 0.0525 \\
\hline & & 75 & 0.0397 \\
\hline & & 90 & 0.0379 \\
\hline & 0.09 & 5 & 0.0610 \\
\hline & & 10 & 0.0501 \\
\hline & & 20 & 0.0423 \\
\hline & & 40 & 0.0397 \\
\hline & & 50 & 0.0364 \\
\hline & & 60 & 0.0305 \\
\hline & 0.15 & 5 & 0.0373 \\
\hline & & 10 & 0.0290 \\
\hline & & 20 & 0.0149 \\
\hline & & 30 & 0.0122 \\
\hline & & 40 & 0.0102 \\
\hline & & 50 & 0.0099 \\
\hline & 0.21 & 5 & 0.0310 \\
\hline & & 10 & 0.0236 \\
\hline & & 15 & 0.0180 \\
\hline & & 20 & 0.0137 \\
\hline & & 25 & 0.0113 \\
\hline & & 30 & 0.0110 \\
\hline \multirow[t]{6}{*}{450} & 0.03 & 20 & 0.0301 \\
\hline & & 40 & 0.0268 \\
\hline & & 80 & 0.0241 \\
\hline & 0.09 & 20 & 0.0104 \\
\hline & & 40 & 0.0100 \\
\hline & & 80 & 0.0083 \\
\hline \multirow[t]{6}{*}{400} & 0.03 & 20 & 0.0340 \\
\hline & & 40 & 0.0293 \\
\hline & & 80 & 0.0244 \\
\hline & 0.09 & 20 & 0.0341 \\
\hline & & 40 & 0.0294 \\
\hline & & 80 & 0.0210 \\
\hline 425 & 0.03 & 40 & 0.0314 \\
\hline 475 & 0.03 & 40 & 0.0201 \\
\hline
\end{tabular}


between the two zones cannot be seen and a monotonically decreasing trend can be considered.

\subsection{Kinetics equation evaluation}

Understanding the mechanism of a reaction is of essence, while not necessary in the reactor design procedures. In fact, what is needed to design a reactor is a rate equation that should be true and accurate at the range of reaction conditions [16]. The reaction of coke-burning can be written as:

$$
\mathrm{C}_{n} \mathrm{H}_{m}+\left(n+\frac{m}{4}\right) \mathrm{O}_{2} \rightarrow \frac{m}{2} \mathrm{H}_{2} \mathrm{O}+n \mathrm{CO}_{2}
$$

Determining the consumed oxygen and produced carbon dioxide by temperature programmed reduction (TPR) indicates that the value of $n$ for the reaction of coke formation on $\mathrm{Pt} / \gamma-\mathrm{Al}_{2} \mathrm{O}_{3}$ varies from $0.5-1$.

The power law form is used to adapt the rate equation expression with the experimental data. Scientific interest in power-law form of the relations stems partly from the ease with which certain general classes of mechanisms generate them. [17] However, the rate of coke combustion reaction on $\mathrm{Pt} / \gamma-\mathrm{Al}_{2} \mathrm{O}_{3}$ is given by:
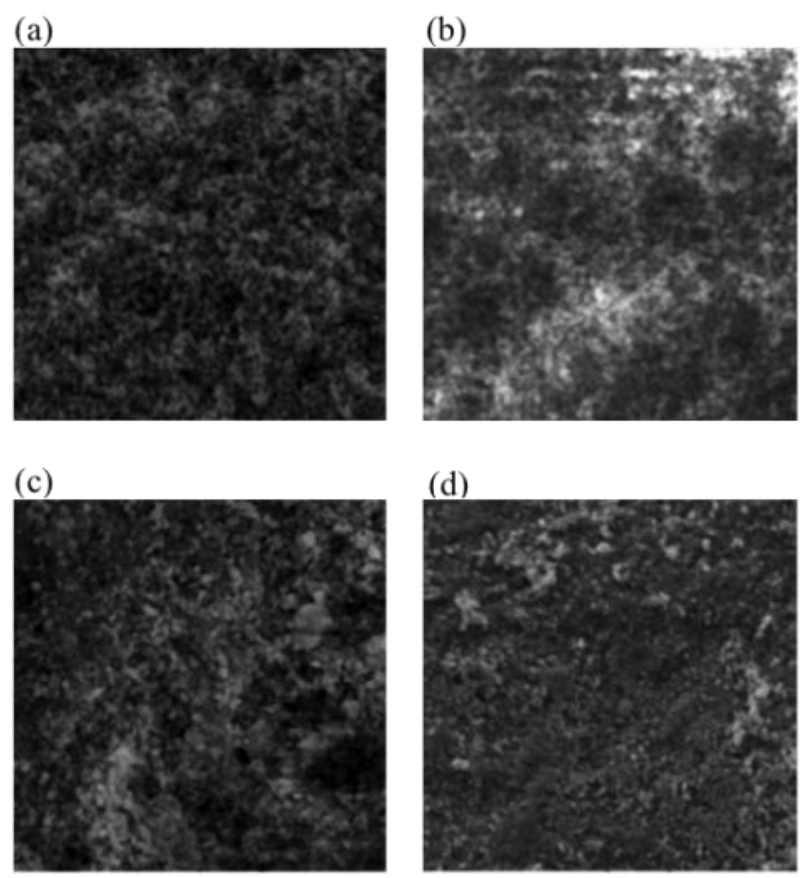

Figure 2. SEM images of the catalyst for the deactivated and regenerated states; for the center of the catalyst ( $a$ and $b$ ) and surface of the catalyst (c and d). Scale bar is $5 \mu \mathrm{m}$ in all the figures

$$
\left(-r_{O_{2}}^{\prime}\right)=K y_{O_{2}}^{a} X^{b}
$$

If the temperature variation range is not so high, the Arrhenius equation is applied with enough accuracy to determine the activation energy and frequency factor of reaction:

$$
K=k_{0} \exp \left(-\frac{E_{A}}{R T}\right)
$$

where, $k_{0}$ is the frequency factor of reaction rate constant. The experimental data of variation of catalyst coke content at different times of reaction for different operating conditions are illustrated in Figure 4. The best exponential $X(t)$ fitting to each set of experimental data obtained through 2D Table curve software, are presented in this figure.

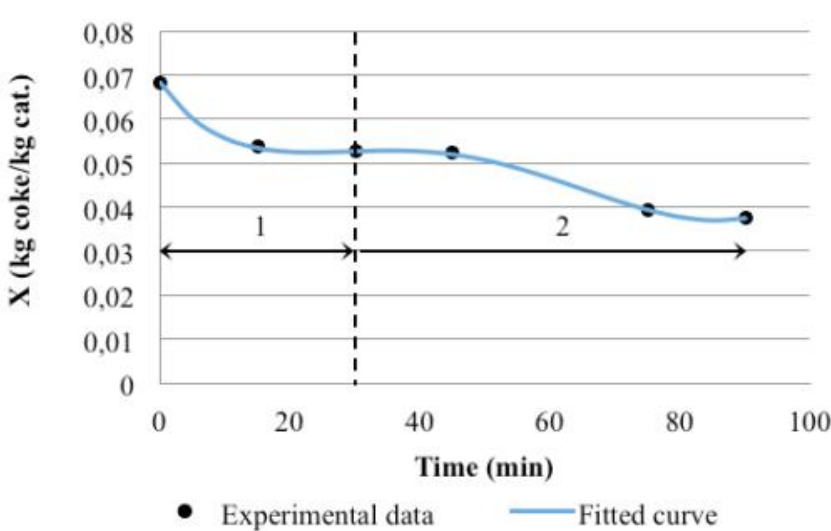

Figure 3. Variation of coke content of catalyst through the decoking process at $500{ }^{\circ} \mathrm{C}, 4.3$ bar and oxygen concentration of $3 \% \mathrm{vol}$.

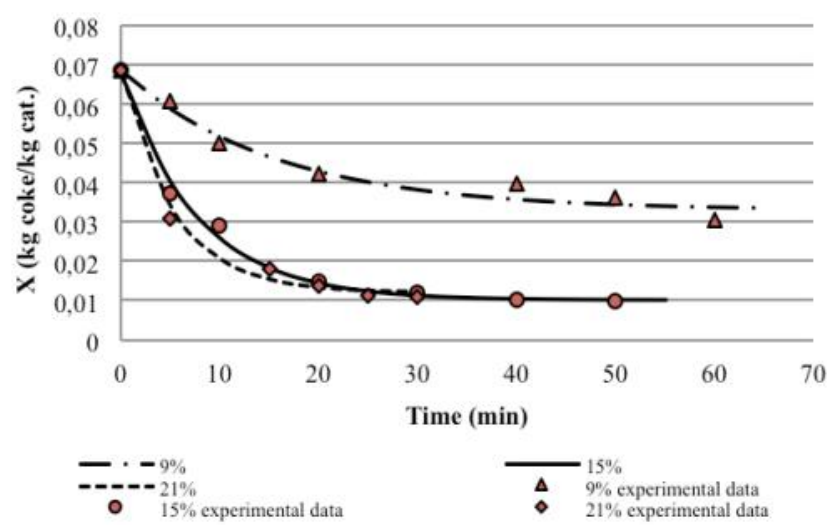

Figure 4. Variation of coke content of catalyst through the decoking process at $500{ }^{\circ} \mathrm{C}$ and 4.3 bar pressure for different oxygen concentrations in decoking gas 
By differentiation of $X(t)$ expression, a new expression for calculating the rate of reaction is obtained. Then the values of reaction rates for corresponding reaction times is obtained now. By using the values of reaction rates, $X$ (coke loads) and $\mathrm{O}_{2}$ compositions through Table curve $3 \mathrm{D}$ software Figure 5 is plotted. As seen in this figure, the reaction order with respect to the oxygen and coke load is 1.27 and 1.66 , respectively.

The value of $E_{A}$ can be determined from the investigation of temperature effect on the rate. The rate constant equation can be written as a linear relation in the following equation:

$$
\ln K=\ln k_{0}-\frac{E_{A}}{R} \times \frac{1}{T}
$$

The experimental data and their results of the linear regression are presented in Figure 6 . As shown in this figure, the $E_{\mathrm{A}} / R$ value is about $8527.8 \mathrm{~K}$.

High values of $R$-squared and the sufficient compatibility between the experimental data and the results of the model indicate that the obtained power law scheme for kinetics model is acceptable and temperamentally all existing phenomena that affect the reaction rate, including the intra-particle mass transfer, have been implemented in the constant parameters of the kinetics model. It seems that the main reason for this goodness of fitting is that the diameter of catalyst pellets used in Pacol reactor is small enough. Thus the intra-particle mass transfer resistance could be ignored and one can assume that the oxygen concentration inside the catalyst pellets is uniform.

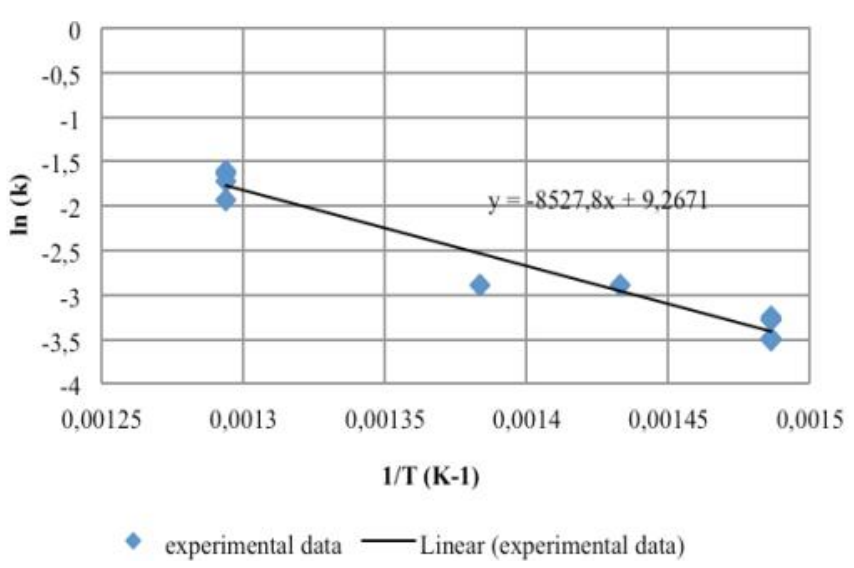

Figure 6. Diagram of Arrhenius equation for coke burning process

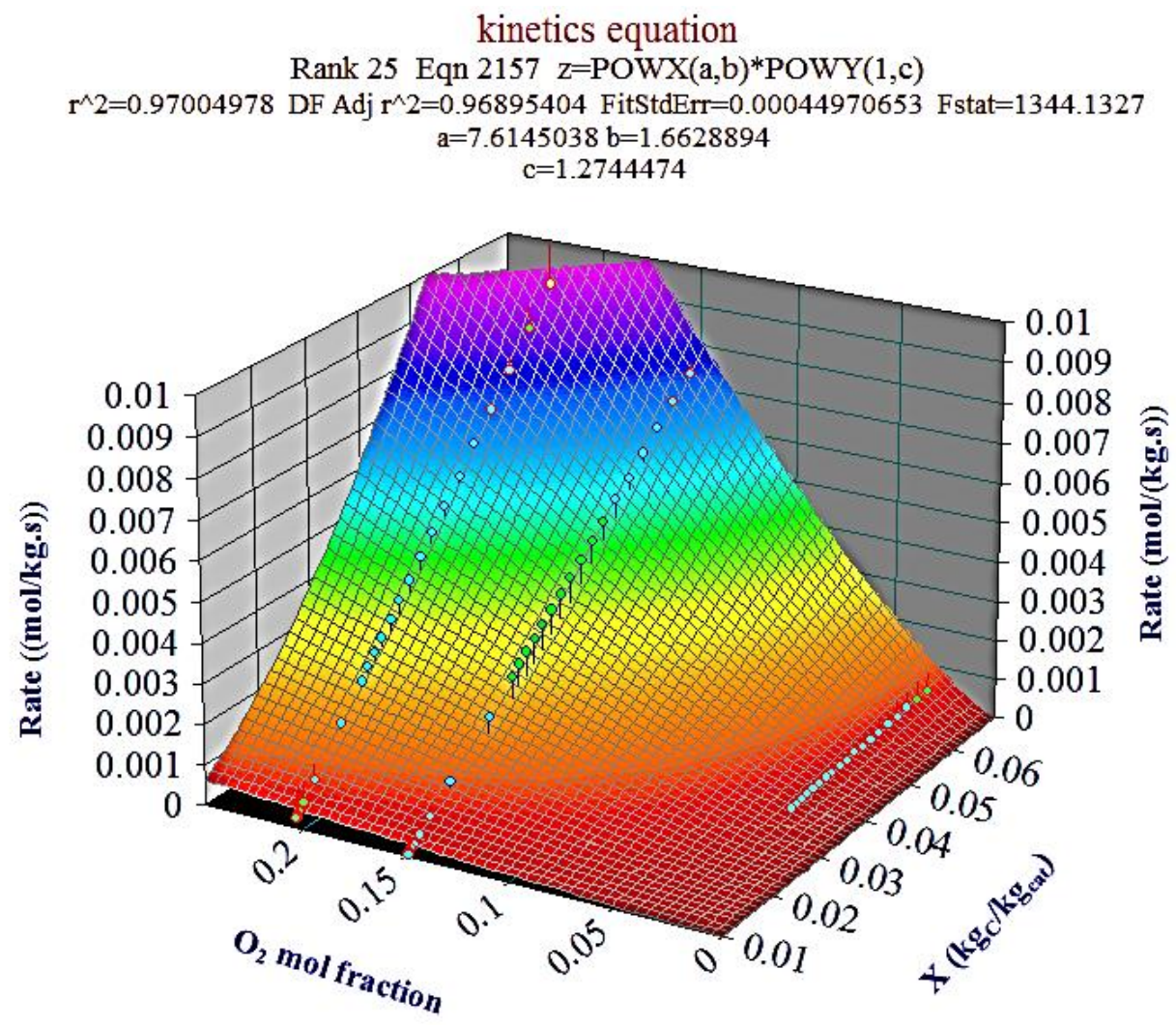

Figure 5. Three-dimensional reaction rate curve fitted by experimental data using the Table Curve $3 \mathrm{D}$ software 


\section{Conclusions}

In this article, the kinetics of decoking process for $\mathrm{Pt} / \gamma-\mathrm{Al}_{2} \mathrm{O}_{3}$ catalyst is investigated. A kinetic model is developed based on data taken from a pilot-scale coke burn off reactor. It is observed that in low compositions of oxygen and low reaction rates, the $X$-time chart is divided into two zones, because of the type of the coke. Whereas, for high reaction rates, such zones cannot be observed; therefore, coke load variations versus time has a monotonic trend. A Three-dimensional reaction rate curve is fitted by experimental data using the Table Curve $3 \mathrm{D}$ software. The reaction order with respect to the oxygen and coke content are 1.27 and 1.66 respectively. The activation energy and coefficient of Arrhenius are determined by a linear regression based on the obtained experimental data in different temperatures. The result indicates that the value of $E_{A} / R$ is about $8527.8 \mathrm{~K}$.

\section{Acknowledgments}

The experimental data used in this research are obtained through collaboration with $R \& D$ department of Iran Chemical Industries Investment Co. (ICIIC). The authors highly appreciate this helpful cooperation. Also the kindly help of Mr. Mirmohammadi, Mr. Beigi, and Mr. Kavianian is greatly appreciated.

\section{References}

[1] Forzatti P., Lietti L. (1999). Catalyst deactivation. Catalysis Today, 52: 165-181.

[2] Cheng, C.K., Chin, S.Y., Chye, J.J.E., Ho, K.S. (2013). Characterization of Industrial Pt$\mathrm{Sn} / \mathrm{Al}_{2} \mathrm{O}_{3}$ Catalyst and Transient Product Formations during Propane Dehydrogenation. Bulletin of Chemical Reaction Engineering \& Catalysis, 8: 77-82.

(DOI:10.9767/bcrec.8.1.4569.77-82)

[3] Istadi, I., Anggoro, D.D., Amin, N.A.S., Ling, D.H.W. (2011). Catalyst deactivation simulation through carbon deposition in carbon dioxide reforming over $\mathrm{Ni} / \mathrm{CaO}-\mathrm{Al}_{2} \mathrm{O}_{3}$ catalyst. Bulletin of Chemical Reaction Engineering \& Catalysis, 6: 129-136.

(DOI: 10.9767/bcrec.6.2.1213.129-136 )

[4] Appleby, W.G., Gibson, J.W., Good, G.M. (1962). Coke Formation in Catalytic Cracking. Industrial \& Engineering Chemistry Process Design and Development, 1: 102-110.

[5] Voge, H.H., Good, J.M., Greensfelder, B.J. (1951). In Proceedings of the Third World Petroleum Congress, 4: 124. The Hague, Netherlands, the Third World Petroleum Congress,
Inc.

[6] Ahmed, R., Sinnathambi, C.M., Subbarao, D. (2011). Kinetics of De-coking of Spent Reforming Catalyst. Journal of Applied Sciences, 11: 1225-1230.

[7] Hashimoto, K., Takatani, K., Iwasa, H., Masuda, T. (1983). A multiple-reaction model for burning regeneration of coked catalysts. The Chemical Engineering Journal, 27: 177-186.

[8] Sampath, B.S., Hughes, R. (1973). A review of mathematical models in single particle gas solid non-catalytic reactions. Chem. Eng. 278: 485-497.

[9] Nakasaka, Y., Tago, T., Konno, H., Okabe, A., Masuda, T. (2012). Kinetic study for burning regeneration of coked MFI-type zeolite and numerical modeling for regeneration process in a fixed-bed reactor. Chemical Engineering Journal, 207-208: 368-376.

[10] Sampath, B.S., Ramachandran, P.A., Hughes, R. (1975). Modelling of non-catalytic gas-solid reactions-II. Transient simulation of a packed bed reactor. Chemical Engineering Science, 30: 135-143.

[11] Kern, C., Jess, A. (2001). Modeling of the regeneration of a coked fixed bed catalyst based on kinetic studies of coke burn-off. Studies in Surface Science and Catalysis, 139: 447-454.

[12] Kern, C., Jess, A. (2005). Regeneration of coked catalysts-modelling and verification of coke burn-off in single particles and fixed bed reactors. Chemical Engineering Science, 60: 4249-4264.

[13] Behroozi, A., Hatamipour, M.S., Rahimi, A. (2012). Mathematical modeling and parametric study of coke-burning process in a hydrocracker reactor. Computers \& Chemical Engineering, 38: 44-51.

[14] Toghyani, M., Rahimi, A., Mirmohammadi, J. (2015). Mathematical Modeling and Parametric Study of Dehydrogenation Catalyst Decoking Process. Applied Catalysis A: General, 489: 226-234.

[15] Xinping, Z., Zhijun, S., Xinggui, Z., Weikang, Y. (2010). Modeling and Simulation of Coke Combustion Regeneration for Coked $\mathrm{Cr}_{2} \mathrm{O}_{3} / \mathrm{Al}_{2} \mathrm{O}_{3}$ Propane Dehydrogenation Catalyst. Chinese Journal of Chemical Engineering, 18: 618-625.

[16] Smith, J.M. eds. (1983). Chemical Engineering Kinetics. McGraw-Hill, New York.

[17] Sornette, d. (2006). Critical Phenomena in Natural Sciences: Chaos, Fractals, Selforganization and Disorder: Concepts and Tools. Springer Berlin Heidelberg. 